Article

\title{
Evaluation of Water Resource Security Based on an MIV-BP Model in a Karst Area
}

\author{
Liying Liu ${ }^{1,2}$, Dongjie Guan ${ }^{3,4, *(1)}$ and Qingwei Yang ${ }^{1}$ \\ 1 College of River and Ocean Engineering, Chongqing Jiaotong University, Chongqing 400074, China; \\ 1ly@ctbu.edu.cn (L.L.); qwyang2001@163.com (Q.Y.) \\ 2 College of Mathematics and Statistics, Chongqing Technology and Business University, Chongqing 400067, \\ China \\ 3 College of Architecture and Urban Planning, Chongqing Jiaotong University, Chongqing 400074, China \\ 4 Key Laboratory of Mountain Town Construction and New Technology, Ministry of Education, \\ Chongqing University, Chongqing 400045, China \\ * Correspondence: guandongjie_2000@163.com; Tel.: +86-185-0238-8076; Fax: +86-023-6278-9033
}

Received: 14 May 2018; Accepted: 11 June 2018; Published: 14 June 2018

\begin{abstract}
Evaluation of water resource security deserves particular attention in water resource planning and management. A typical karst area in Guizhou Province, China, was used as the research area in this paper. First, based on data from Guizhou Province for the past 10 years, the mean impact value-back propagation (MIV-BP) model was used to analyze the factors influencing water resource security in the karst area. Second, 18 indices involving five aspects, water environment subsystem, social subsystem, economic subsystem, ecological subsystem, and human subsystem, were selected to establish an evaluation index of water resource security. Finally, a BP artificial neural network model was constructed to evaluate the water resource security of Guizhou Province from 2005 to 2014. The results show that water resource security in Guizhou, which was at a moderate warning level from 2005 to 2009 and a critical safety level from 2010 to 2014, has generally improved. Groundwater supply ratio, industrial water utilization rate, water use efficiency, per capita grain production, and water yield modulus were the obstacles to water resource security. Driving factors were comprehensive utilization rate of industrial solid waste, qualifying rate of industrial wastewater, above moderate rocky desertification area ratio, water requirement per unit gross domestic product (GDP), and degree of development and utilization of groundwater. Our results provide useful suggestions on the management of water resource security in Guizhou Province and a valuable reference for water resource research.
\end{abstract}

Keywords: BP neural network; karst; MIV; water resource security

\section{Introduction}

Water is widely regarded as the most essential natural resource [1]. With the rapid development of the global economy and population growth, a series of water-related problems have attracted much attention. Nearly $80 \%$ of the world's population is exposed to high levels of threat to water security [2]. Water resources constitute the core element of the ecological socioeconomic system and are the foundation of natural, strategic, and economic resources [3]. Water resource security is an important concept that was proposed by the international community at the end of the 20th century and has become one of the problems of human security, along with economic security, food security, and military security [4]. Whether water resources are safe is highly determined by natural phenomena and ecological changes. As a consequence, research on water resource security has become a hot issue in water science [5-7], and plays an important role in understanding sustainable regional ecological 
and environmental development. In general, developing and managing water resources to achieve water security remains at the heart of the struggle for growth, sustainable development, and poverty reduction [8].

Water resource security analyses to date have focused on a range of sectors (e.g., agriculture, potable water, ecosystem services) and scales (e.g., household, nation/state, river basin), and have considered the emerging challenges brought about by climate change, population growth, rapid urbanization, the water-food-energy nexus, and so on. Numerous approaches have been proposed to perform water resource security analysis. For example, a system dynamics model was applied to assess the water resource situation in Tieling city, China, under different scenarios $[9,10]$ presented a vague set-based water resource security evaluation method and established a similarity measure model of vague sets; and an entropy-weighted set pair model was used for Chongqing's water resource security [3]. These analyses advance different interpretations of water resource security, and existing approaches generally emphasize risks, rights, environmental sustainability and adaptation, and water quality. Meanwhile, there is no in-depth research on an analytical or diagnostic model for assessing water resource security, especially considering the complexity and nonlinear behavior of water resource systems.

Currently, research on China's water resource security is mainly focused on the traditional areas of water scarcity, such as the northwest arid region [11] and northern China [12,13], while less effort has been made in the karst region of southwest China. Nevertheless, karst is a unique environment on the earth, characterized by distinctive landforms and hydrological features. Not surprisingly, water resource security has also been a central focus in karst areas. There has also been a focus on the relationship between karst water resource security and modern resource use [14], human impacts [15], and atmosphere [16]. Despite the growing importance of the topic, an analytical framework for assessing water resource security in karst areas is not known to exist.

Artificial neural network (ANN), which has a wide range of adaptability and learning ability, has been widely accepted as a technology offering an alternative way to simulate complex and ill-defined problems. It is one of the most active research fields in the world, and will be widely used in the study of ecological security [17]. It can effectively solve the nonlinear fuzzy problem in the water resource system by self-learning and self-adapting to representative samples, to describe the coupling of water resources and social economic systems. Therefore, it is easy to make an objective and correct evaluation of water resource security with ANN. Furthermore, back-propagation (BP) neural networks have been widely used in the sustainable utilization of water resources [18], water quality evaluation [19], land ecological security assessment [20], and so on. For example, there is better appreciation of flash flood forecasting [21] and karst groundwater management [22] based on neural networks. However, the BP algorithm applied to the research of water resource security in karst areas is still in its infancy at home and abroad.

Aiming to elucidate the complicated influence factors and the current situation of water resource security in karst areas, this study takes a typical karst area in Guizhou Province as the research object. Mean impact value (MIV) and back-propagation (BP) neural network are used with statistical data from 2005 to 2014 in Guizhou Province. Our results will not only contribute further understanding of water resource security evaluation, but also highlight important practical significance to promote sustainable utilization of karst water resources.

\section{Study Area}

Guizhou Province, in southwest China, is a typical karst region located at longitude $103^{\circ} 36^{\prime} \mathrm{E}-109^{\circ} 35^{\prime} \mathrm{E}$ and latitude $24^{\circ} 37^{\prime} \mathrm{N}-29^{\circ} 13^{\prime} \mathrm{N}$ (Figure 1). It covers an area of $176,167 \mathrm{~km}^{2}$, with an average elevation of about $1100 \mathrm{~m}$. The karst area spans about $61.9 \%$ of the province and is characterized by soluble carbonate rocks. Guizhou has a subtropical highland humid monsoon climate, featuring abundant rainfall and indistinct seasonal differences. With an annual rainfall of 1100-1400 mm, the amount of surface water resources is more than 120 billion $\mathrm{m}^{3}$. Meanwhile, due to the strong karst evolution, 
water resources are seriously affected. The per capita share is slightly higher than the national average, but the usable amount is lower than the national average. The annual consumption of water is about 10 billion $\mathrm{m}^{3}$. The consumption of agricultural water makes up the largest proportion, about half of the total water consumption, while ecological water consumption is the least, with a proportion of less than $1 \%$.

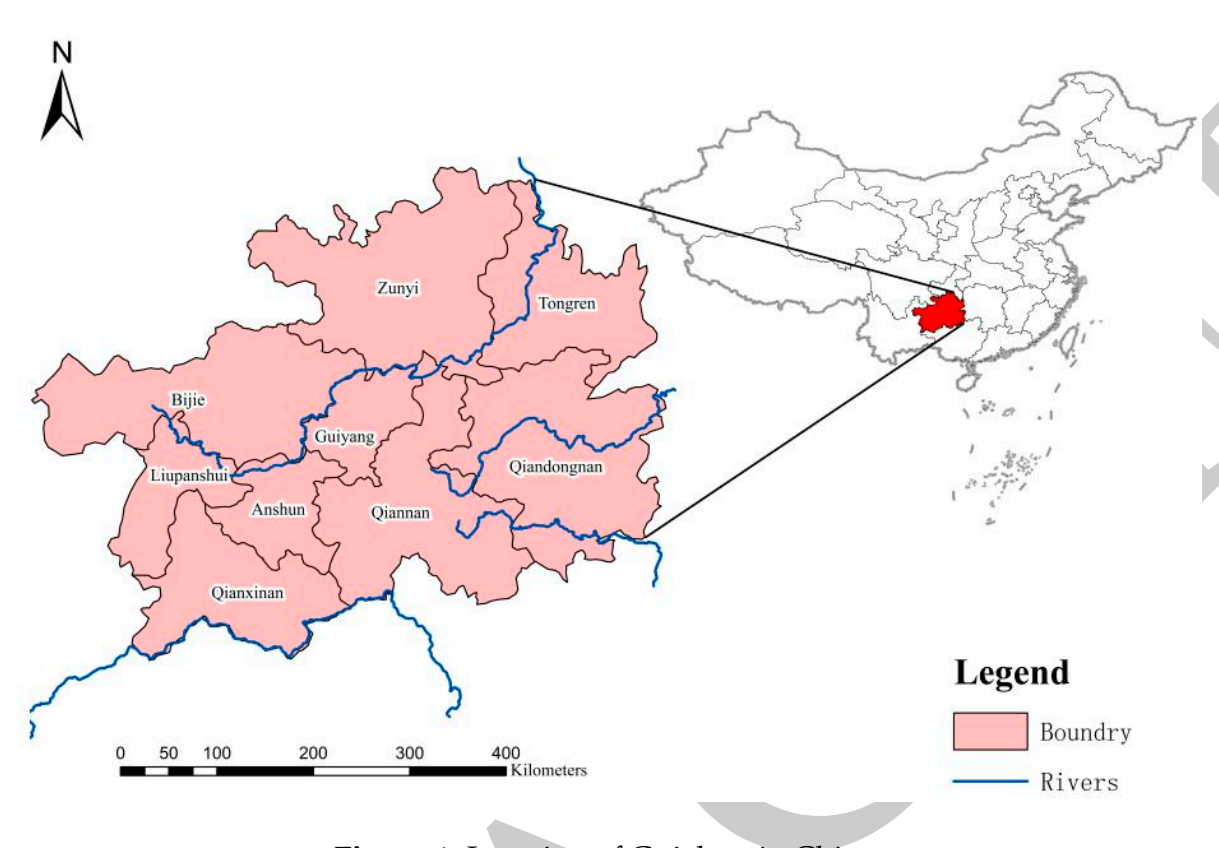

Figure 1. Location of Guizhou in China.

\subsection{Materials and Methodology}

Construction of Primary Evaluation Index System

A water resource system is a compound system. To evaluate water resource security under changing situations, the system needs to be studied from an objective and systematic perspective. To analyze what water resource security means, the system is categorized into 5 subsystems: water environment subsystem, social subsystem, economic subsystem, ecological subsystem, and human subsystem (water resource management and policy regulation). The interactions among these 5 subsystems forms a dynamically changing water resource security system. To achieve the overall security of water resources, each subsystem should not only achieve its own security status, but also have benign interactions with the others.

According to the situation of a karst area, this study builds a primary evaluation index system of water resource security based on the above 5 subsystems. The primary evaluation index contains 30 indices, with water consumption per capita as a dependent variable (Table 1). Water resource assessment is difficult due to the complicated hydrogeological conditions in the karst groundwater area. The index selection is mainly considered to be confined to the social, economic, environmental, and ecological contexts. However, groundwater quality in the karst region as determined by the statistical data is excellent: $94 \%$ of the groundwater environmental quality is beyond good. Therefore, in this paper, groundwater quality is not taken into account. 
Table 1. Primary evaluation index system of water resource security in karst areas.

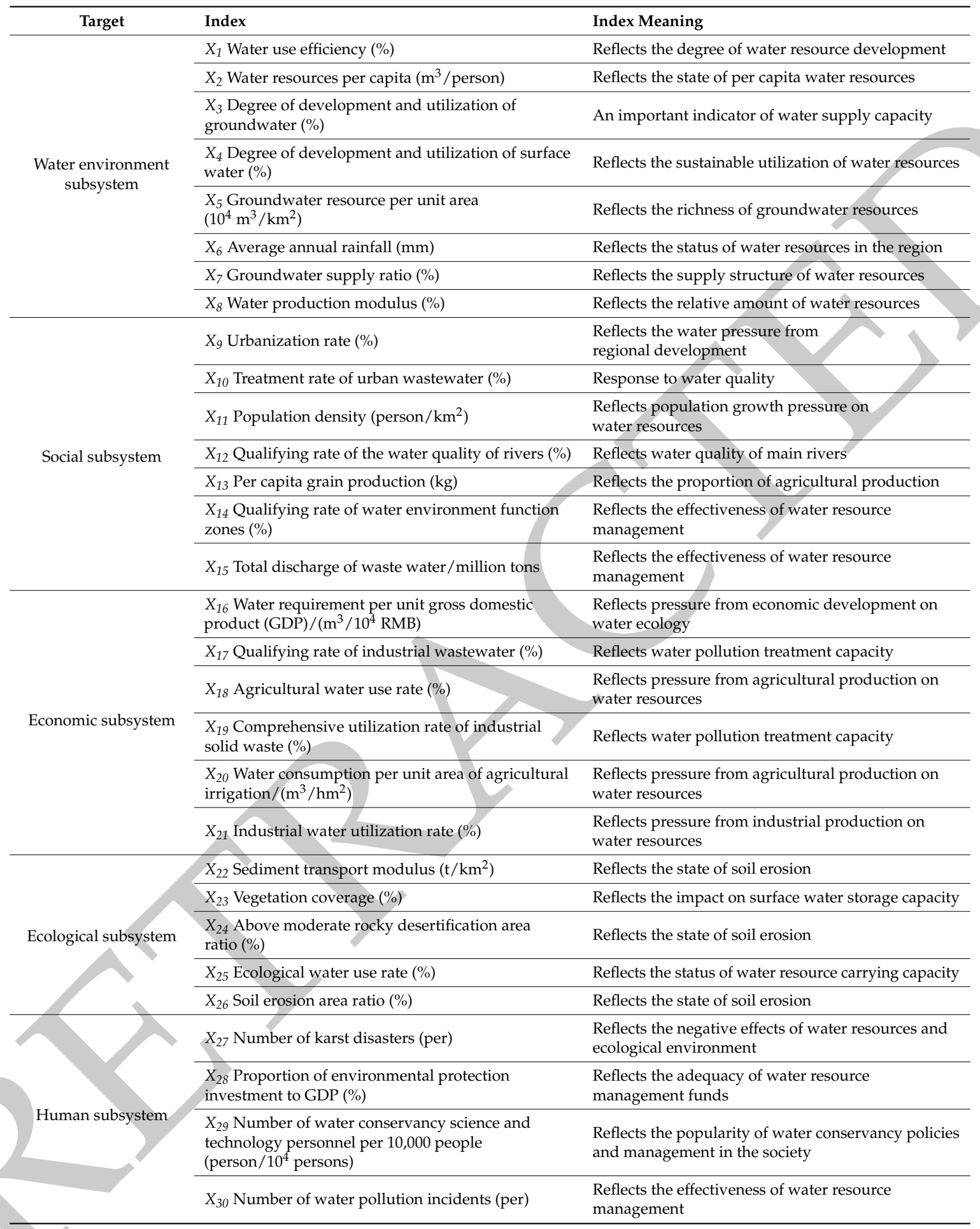

\subsection{Construction of MIV-BP Model for Variable Selection}

To evaluate the security of water resources, it is necessary to select as many of the most representative indices as possible from the primary indices and remove the nonsignificant ones. Mean impact value (MIV) is considered to be one of the best algorithms to evaluate the correlation among indices [23]. Therefore, combining the BP neural network with the MIV, the primary indices were determined by way of quantitative screening, to build the final evaluation index system. 
First, the BP neural network is trained and simulated. After training, each of the independent variables in training sample $P$ is added and subtracted by $10 \%$ on the basis of its original value to form 2 new training samples, $P_{1}$ and $P_{2}$. Second, $P_{1}$ and $P_{2}$, as simulation samples, are simulated using the built network, and 2 simulation results, $A_{1}$ and $A_{2}$, are obtained. The difference between $A_{1}$ and $A_{2}$ is calculated, that is, the impact value (IV) of the output dependent variable is gotten after changing the independent variable. All IV values are averaged by the number of observations to give the mean impact value (MIV) of the independent variable. Lastly, according to the above steps, the MIV of each independent variable is calculated, and then the variables are sorted according to the absolute value of MIV to determine the influence of input parameters on the output variables.

The number of input neurons in the network is 30 , and the number of output neurons is 1 . After training, it is concluded that when the number of neurons in the hidden layer is 7 , the network error is the smallest, and the neural network structure is set to the 3-layer neural network. The maximum number for training is set to 5000 , the learning rate is set to 0.05 , and the target error is set to 0.0001 .

A procedure to create the network is written as net=newff(minmax (p), [7,1], \{'tansig', 'purelin'\},'traingdm'). After normalization of input and output data, the BP neural network training process is as shown in Figure 2. It can be seen that neural network error reaches the target error of 0.0001 only after 2583 trainings; the error results meet the training requirements. The model can be judged according to $R$ value. The closer $R$ is to 1 , the better the model and the higher the prediction accuracy It can be seen from Figures 3 and 4 that all validation checks and gradients of the model decrease as training times. The mean square error is close to 1 and error gradient descent is 0.0024 , so the neural network fits well with the training data. The trained network can better predict the training data.

According to the trained BP neural network, the output of the predicted data is simulated and the MIV is calculated. The absolute value of MIV indicates the importance of water resource security in the karst area, which is chosen as the basis for selection of the water resource security evaluation index. That is, the more important the index is, the higher the MIV value should be.

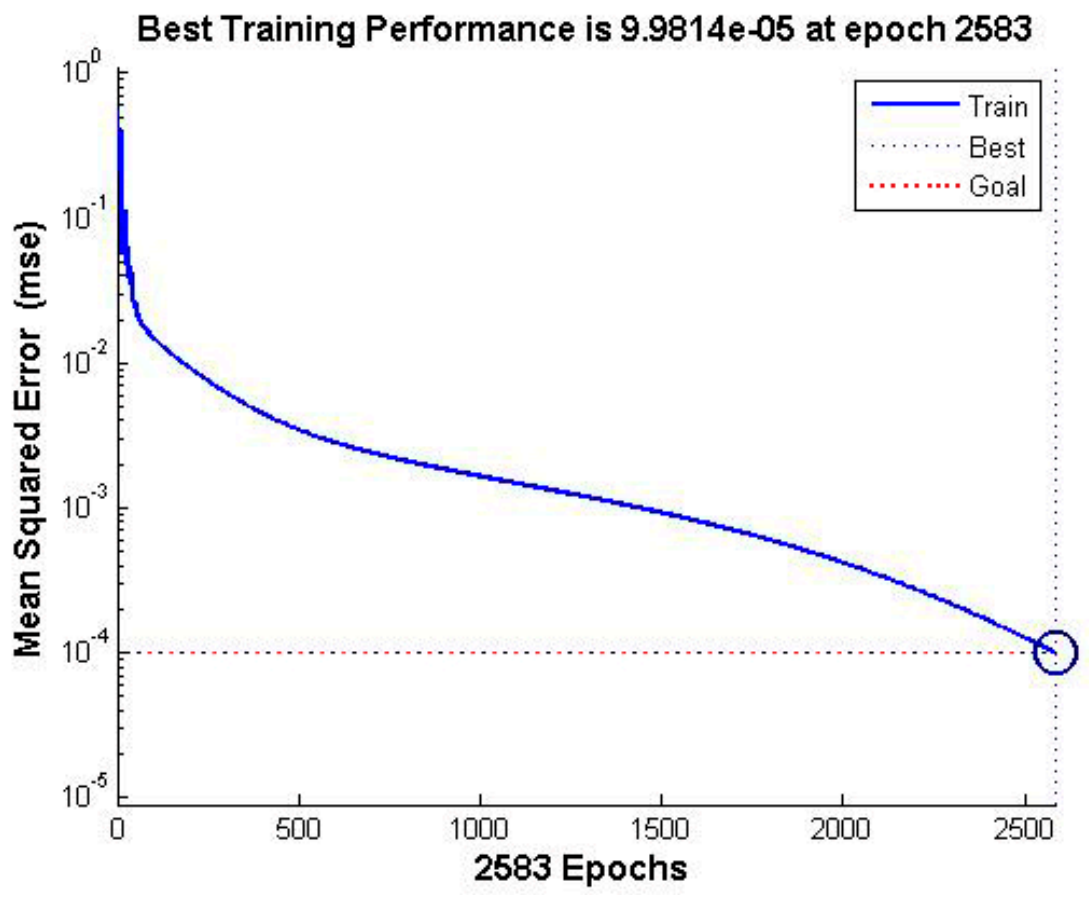

Figure 2. Effect of neural network training. 

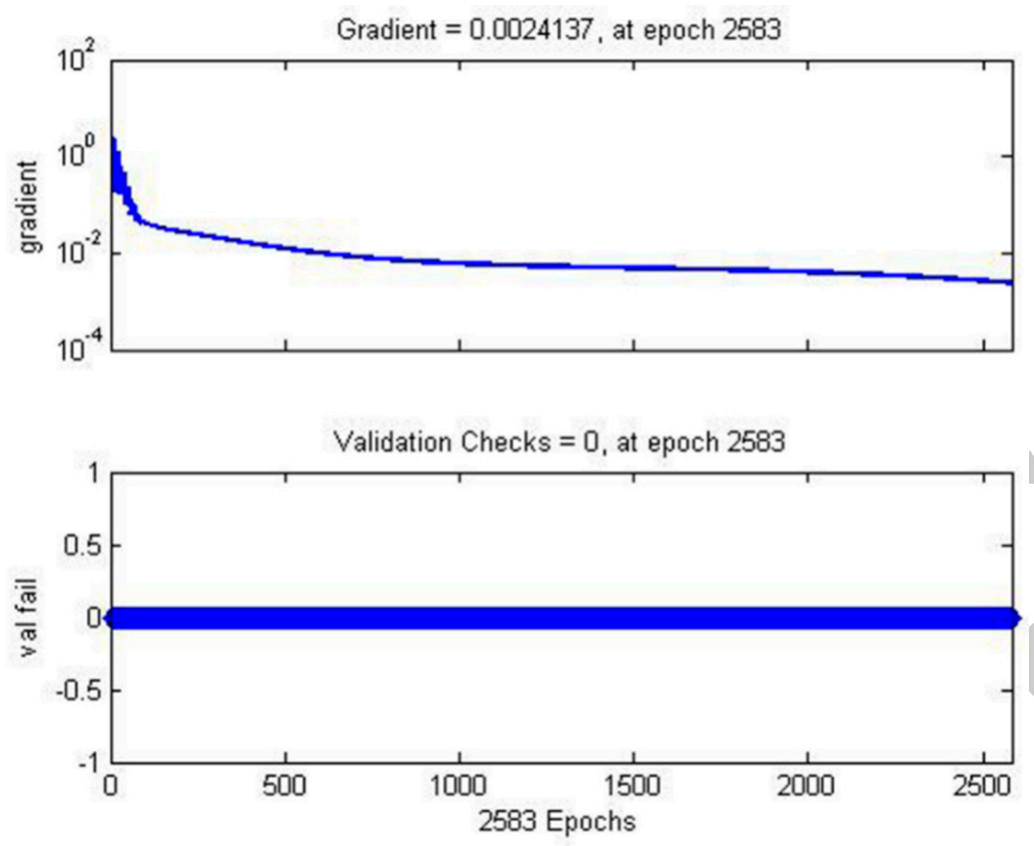

Figure 3. Training parameters of neural network.

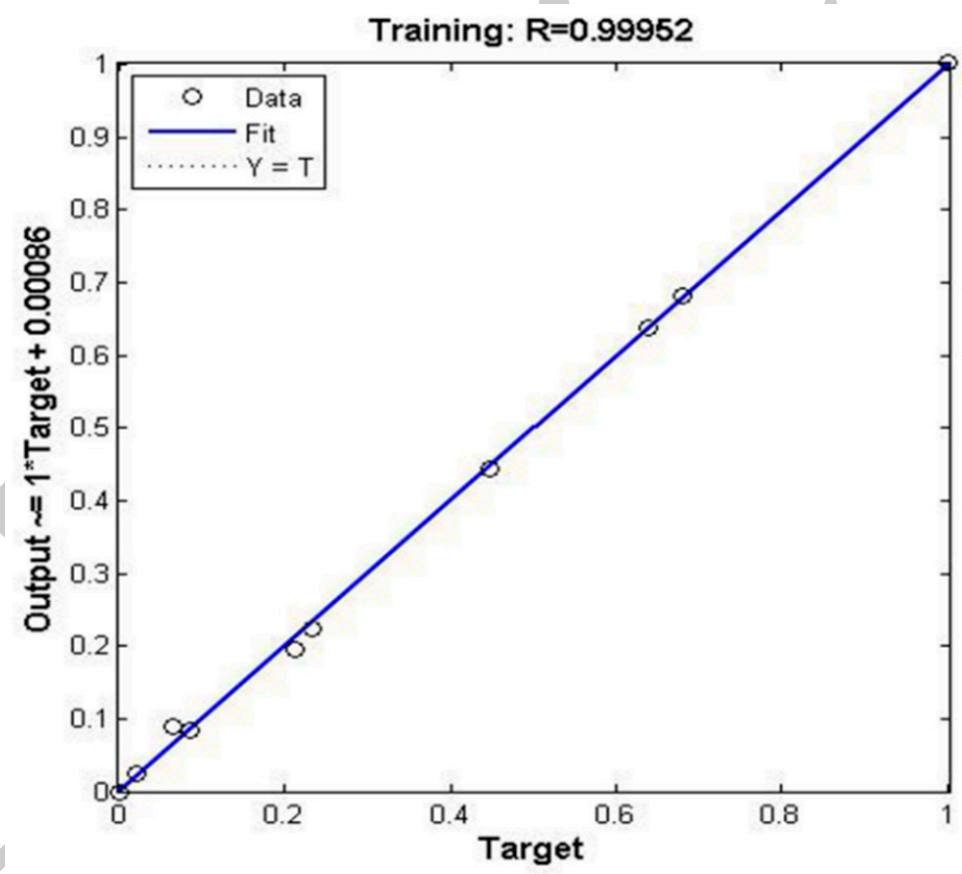

Figure 4. Regression analysis of neural network training.

2.3. Screening Results of Evaluation Indices Based on the MIV-BP Model

The importance of each index on the impact of water resource security in the karst area is sorted by absolute value, as shown in Table 2. 
Table 2. Mean impact values (MIVs) of water resource security influence factors in the karst area.

\begin{tabular}{|c|c|c|}
\hline Index & MIV & Order \\
\hline$X_{7}$ Groundwater supply ratio (\%) & 0.0436 & 1 \\
\hline$X_{19}$ Comprehensive utilization rate of industrial solid waste $(\%)$ & -0.0328 & 2 \\
\hline$X_{17}$ Qualifying rate of industrial wastewater $(\%)$ & -0.0277 & 3 \\
\hline$X_{21}$ Industrial water utilization rate $(\%)$ & 0.022 & 4 \\
\hline$X_{24}$ Above moderate rocky desertification area ratio (\%) & -0.0214 & 5 \\
\hline $\mathrm{X}_{16}$ Water requirement per unit GDP $\left(\mathrm{m}^{3} / 10^{4} \mathrm{RMB}\right)$ & -0.0194 & 6 \\
\hline$X_{1}$ Water use efficiency $(\%)$ & 0.0189 & 7 \\
\hline$X_{13}$ Per capita grain production $(\mathrm{kg})$ & 0.0185 & \\
\hline$X_{3}$ Degree of development and utilization of groundwater $(\%)$ & -0.0162 & 9 \\
\hline$X_{8}$ Water production modulus $(\%)$ & 0.015 & 10 \\
\hline$X_{6}$ Average annual rainfall $(\mathrm{mm})$ & 0.0148 & 11 \\
\hline$X_{26}$ Soil erosion area ratio $(\%)$ & & \\
\hline$X_{10}$ Treatment rate of urban wastewater $(\%)$ & -0.0144 & 13 \\
\hline$X_{4}$ Degree of development and utilization of surface water (\%) & 0.014 & 14 \\
\hline$X_{9}$ Urbanization rate $(\%)$ & -0.0137 & 15 \\
\hline$X_{20}$ Water consumption per unit area of agricultural irrigation $\left(\mathrm{m}^{3} / \mathrm{hm}^{2}\right)$ & 0.0113 & 16 \\
\hline$X_{28}$ Proportion of environmental protection investment to GDP (\%) & -0.0105 & 17 \\
\hline$X_{15}$ Total discharge of wastewater (million tons) & 0.01 & 18 \\
\hline$X_{23}$ Vegetation coverage $(\%)$ & -0.0091 & 19 \\
\hline $\begin{array}{c}X_{29} \text { Number of water conservancy science and technology personnel per } \\
10,000 \text { people (person } / 10^{4} \text { persons) }\end{array}$ & -0.0086 & 20 \\
\hline$X_{2}$ Water resources per capita $\left(\mathrm{m}^{3} /\right.$ person $)$ & -0.0077 & 21 \\
\hline$X_{30}$ Number of water pollution incidents (per) & 0.0066 & 22 \\
\hline$X_{2}$ Sediment transport modulus $\left(\mathrm{t} / \mathrm{km}^{2}\right)$ & -0.0065 & 23 \\
\hline$X_{11}$ Population density (person $/ \mathrm{km}^{2}$ ) & 0.0043 & 24 \\
\hline$X_{12}$ Qualifying rate of water quality of rivers (\%) & -0.0042 & 25 \\
\hline$X_{5}$ Groundwater resources per unit area $\left(10^{4} \mathrm{~m}^{3} / \mathrm{km}^{2}\right)$ & -0.0033 & 26 \\
\hline $\mathrm{X}_{18}$ Agricultural water use rate $(\%)$ & 0.0021 & 27 \\
\hline$X_{25}$ Ecological water use rate $(\%)$ & 0.0006 & 28 \\
\hline$X_{27}$ Number of karst disasters (per) & -0.0004 & 29 \\
\hline$X_{14}$ Qualifying rate of water environment function zones (\%) & -0.00008 & 30 \\
\hline
\end{tabular}

Notes: For MIV values, + indicates the positive effect on the increase in water resource security deviation; conversely, it is negative.

\subsection{Grade Classification of Water Resource Security}

According to Table 2, the index system of water resource security evaluation in the karst area is constructed by selecting the first 18 indices with MIV greater than 0.01 .

Referring to the relevant domestic and foreign standards, the index is divided into 5 grades, severe warning level, moderate warning level, critical safety level, moderate safety level, and safety level, which are marked I, II, III, IV, and V (Table 3). 
Table 3. Grade classification of water resource security in the karst area.

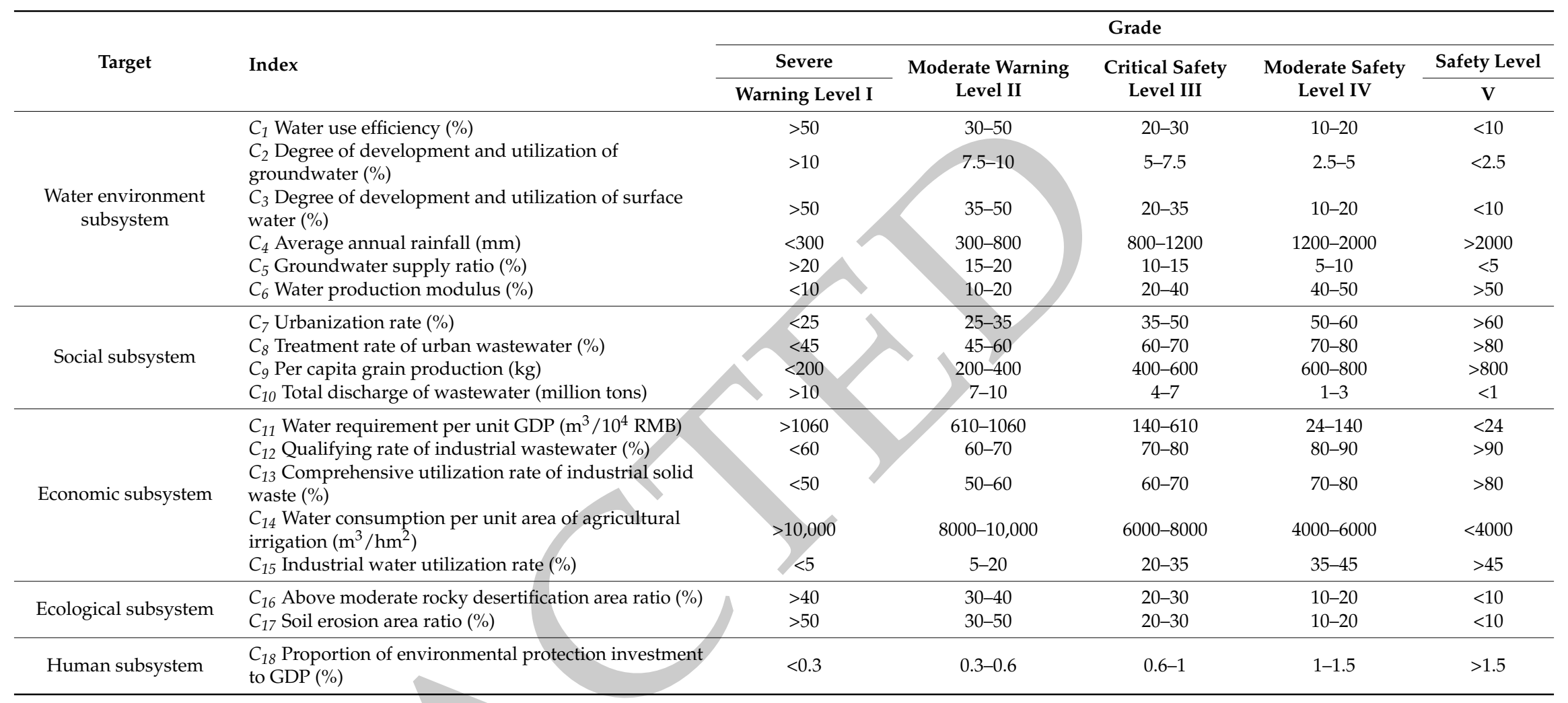




\subsection{Data Sources and Processing}

Primary data were obtained mainly from the Guizhou water resource bulletin (2005-2014) published by the Guizhou Water Resources Bureau, the Guizhou Province environmental status bulletin (2005-2014) published by the Guizhou Environmental Protection Bureau, the Guizhou national economic and social development statistical bulletin (2005-2014) published by the Guizhou Statistical Bureau, and the Guizhou statistical yearbook (2005-2014) published by the Guizhou Statistical Bureau. The data are shown in Table 4.

The data were first normalized to eliminate the data dimension. In this paper, the maximum and minimum methods are used; the formula is: $x_{i j}=\frac{X_{i j}-X_{\min }}{X_{\max }-X_{\min }}$, where $X_{\max }$ and $X_{\min }$ are the maximum and minimum values of the data, respectively, and $X_{i j}$ is the actual observed value of the index. 
Table 4. Data of water resource security evaluation index in karst area, Guizhou (2005-2014).

\begin{tabular}{|c|c|c|c|c|c|c|c|c|c|c|c|}
\hline \multirow{2}{*}{ Target } & \multirow{2}{*}{ Index } & \multicolumn{10}{|c|}{ Index Value } \\
\hline & & 2005 & 2006 & 2007 & 2008 & 2009 & 2010 & 2011 & 2012 & 2013 & 2014 \\
\hline \multirow{6}{*}{$\begin{array}{c}\text { Water } \\
\text { environment } \\
\text { subsystem }\end{array}$} & $C_{1}$ Water use efficiency $(\%)$ & 11.6 & 12.3 & 9.29 & 8.9 & 9.5 & 8.9 & 15.2 & 9.4 & 12.1 & 7.85 \\
\hline & $C_{2}$ Degree of development and utilization of groundwater (\%) & 3.18 & 3.12 & 2.39 & 2.98 & 2.8 & 2.86 & 0.51 & 0.43 & 0.81 & 0.95 \\
\hline & $C_{3}$ Degree of development and utilization of surface water $(\%)$ & 8.66 & 11.31 & 8.66 & 8.2 & 10.23 & 9.8 & 14.74 & 9.11 & 11.85 & 7.49 \\
\hline & $C_{4}$ Average annual rainfall $(\mathrm{mm})$ & 1129.7 & 1015.1 & 1160 & 1266.5 & 949.9 & 1105.9 & 820.6 & 1117.1 & 981.9 & 1384.1 \\
\hline & $C_{5}$ Groundwater supply ratio (\%) & 8.58 & 7.34 & 6.33 & 7.74 & 6.95 & 7.1 & 1.2 & 1.2 & 2.1 & 2.9 \\
\hline & $C_{6}$ Water production modulus (\%) & 56.24 & 46.24 & 59.86 & 64.78 & 51.68 & 54.3 & 35.55 & 55.29 & 43.11 & 68.86 \\
\hline \multirow{4}{*}{ Social subsystem } & $C_{7}$ Urbanization rate $(\%)$ & 26.87 & 27.42 & 28.2 & 29.11 & 30 & 33.81 & 35 & 36.5 & 37.8 & 40.01 \\
\hline & $C_{8}$ Treatment rate of urban wastewater $(\%)$ & 21.1 & 21.2 & 29 & 31.18 & 42.01 & 74.8 & 82 & 83.9 & 84.84 & 86.87 \\
\hline & $C_{9}$ Per capita grain production $(\mathrm{kg})$ & 308.86 & 281.3 & 303.1 & 322.02 & 330.3 & 319.71 & 252.78 & 309.93 & 294.11 & 324.54 \\
\hline & $C_{10}$ Total discharge of wastewater (million tons) & 5.57 & 5.54 & 5.51 & 5.59 & 5.92 & 8.45 & 7.8 & 9.14 & 9.31 & 11.09 \\
\hline \multirow{5}{*}{$\begin{array}{l}\text { Economic } \\
\text { subsystem }\end{array}$} & $C_{11}$ Water requirement per unit GDP $\left(\mathrm{m}^{3} / 10^{4} \mathrm{RMB}\right)$ & 509 & 442 & 339.9 & 286.11 & 256.55 & 220.44 & 167 & 135 & 115 & 103 \\
\hline & $C_{12}$ Qualifying rate of industrial wastewater $(\%)$ & & 71.84 & 71.92 & 80.3 & 81.6 & 82.3 & 85.6 & 86.8 & 88.9 & 89.5 \\
\hline & $C_{13}$ Comprehensive utilization rate of industrial solid waste (\%) & 34.1 & 35.6 & 37.5 & 39.9 & 45.6 & 50.9 & 52.7 & 60.9 & 50.5 & 56.9 \\
\hline & $C_{14}$ Water consumption per unit area of agricultural irrigation $\left(\mathrm{m}^{3} / \mathrm{hm}^{2}\right)$ & 9390 & 7545 & 7545 & 7815 & 7095 & 7815 & 5640 & 6315 & 5805 & 5745 \\
\hline & $C_{15}$ Industrial water utilization rate $(\%)$ & 28.6 & 27.3 & 32.43 & 33.1 & 34 & 38.8 & 42.2 & 27.3 & 29.4 & 29 \\
\hline \multirow{2}{*}{$\begin{array}{l}\text { Ecological } \\
\text { subsystem }\end{array}$} & $C_{16}$ Above moderate rocky desertification area ratio (\%) & 20.39 & 20.39 & 20.39 & 20.39 & 20.39 & 20.39 & 17.16 & 17.16 & 17.16 & 17.16 \\
\hline & $C_{17}$ Soil erosion area ratio $(\%)$ & 41.54 & 41.54 & 41.54 & 41.54 & 41.54 & 31.37 & 31.37 & 31.37 & 29.23 & 29.23 \\
\hline $\begin{array}{l}\text { Human } \\
\text { subsystem }\end{array}$ & $C_{18}$ Proportion of environmental protection investment to GDP (\%) & 1.66 & 1.4 & 1.69 & 1.42 & 1.78 & 1.95 & 2.32 & 1.42 & 1.65 & 1.89 \\
\hline
\end{tabular}




\section{Model Construction}

A BP artificial neural network was used to evaluate water resource security in the karst area. The modeling procedure is described as follows:

(1) Determine the number of network layers: the model consists of three layers (input, output, and hidden layers); the number of input neurons is 18 and the number of output neurons is 1.

(2) Determine the number of hidden neurons: The number of neurons in the hidden layer is based on the empirical formula: $n_{1}=\sqrt{n+m}+\alpha$ ( $n$ and $m$ are the number of neurons in the input layer and output layer, respectively; $\alpha$ is between 1 and 10). By comparing the number of nodes with different hidden layers, the BP network model involving 18 input nodes, 6 intermediate nodes, and 1 output node is established, which is assigned the structure 18-6-1.

(3) Data dimensionless processing: the sample is normalized by the formula: $x_{i j}=\frac{X_{i j}-X_{\min }}{X_{\max }-X_{\min }}$. The annual data is one sample, the number of samples is $i=1,2, \ldots, 10$, and the number of indices is $j=1,2, \ldots, 18$.

(4) BP network training: Activation function is "SIGMOID," training function is "TRAINLM," learning function is "LEARNGDM," and performance function is "MSE." Network creation:

net=newff (minmax(p), [6,1], \{'tansig','logsig'\},'trainlm','learngdm', 'mse'). The outputs of the samples at each level are set as follows: severe warning level (0-0.125), moderate warning level $(0.125-0.375)$, critical safety level $(0.375-0.625)$, moderate safety level $(0.625-0.875)$, and safety level (0.875-1).

According to the classification standard given in Table 3, 10 learning samples were randomly generated for each level, so 50 learning samples were generated. The data of the 50 samples were normalized and their corresponding target values were used to form the training samples. The training time was set for 1000 times, and learning parameters were set for $\eta=0.1, \alpha=0.9, E \leq 0.00001$. The training samples were input to the BP network built for training. When the error iteration was 331 times, the error was 0.0452, which satisfied the error requirement. The BP network model for evaluation of water resource security can be put to use.

\section{Results and Discussion}

\subsection{Analysis of Factors Influencing Water Resource Security in the Karst Area}

\section{Main Factors Influencing Water Resource Security in the Karst Area}

As can be seen from Table 2, the factors influencing water resource security with MIVs larger than 0.01 are groundwater supply ratio, water use efficiency, degree of development and utilization of groundwater, degree of development and utilization of surface water, water production modulus, and average annual rainfall from the water environment subsystem; urbanization rate, treatment rate of urban wastewater, per capita grain production, and total discharge of wastewater from the social subsystem; water requirement per unit GDP, qualifying rate of industrial wastewater, comprehensive utilization rate of industrial solid waste, water consumption per unit area of agricultural irrigation, and industrial water utilization rate from the economic subsystem; above moderate rocky desertification area ratio and soil erosion area ratio from the ecological subsystem; and proportion of environmental protection investment to GDP from the human subsystem. The greater the absolute value of MIV, the greater influence the factor has on water resource security in the karst area; if it is the contrary, the influence is smaller. It can be seen that the influence of the water environment and economic subsystems is much greater than that of the ecological and human subsystems, while the social subsystem is between them.

In the karst area, the ecological environment factor has a weak influence based on the implementation of environmental protection in Guizhou Province. 
According to the differentiation information of the indicators, the forest coverage rate of the study area increased year by year, reaching $49 \%$ in 2014, while both soil erosion area ratio and above-moderate rocky desertification area ratio decreased year by year. The study area covers about $9500 \mathrm{~km}^{2}$, accounting for $5.4 \%$ of the province's land area. Therefore, the ecological subsystem has a smaller influence on evaluating water resource security.

\subsection{Obstacles to Water Resource Security in the Karst Area}

According to Table 2, the top 10 indices with significant effects on water resource security in the karst area were analyzed. The results show that groundwater supply ratio, industrial water utilization rate, water use efficiency, per capita grain production, and water production modulus contribute significantly to the deviation of water resource security. For each additional standard deviation unit, the positive contribution to the deviation of water resource security is $0.0436,0.022,0.0189,0.0185$, and 0.015 , respectively. These five indices are the main obstacles to water resource security in recent years. As can be seen from Figure 5, these five indices show volatility in the tendency to be detrimental to water resource security. Water resource security is restricted by social economy, population, and natural environment in the karst area. It is difficult to develop and utilize water resources because of the limitation of topographical conditions, with steep slope, small terrain plots, simple vegetation structure, and underground fissures. Seasonal drought is caused by the large variation coefficient of precipitation, together with special karst landform and weak surface storage. During the study period, Guizhou experienced a severe drought from 2009 to 2011, and again in 2013. The system of social economy, population growth, backward agricultural production, rapid industrial development, and changes in degree and manner of development and utilization of water resources have a negative impact on water resource security. Therefore, exploitation and utilization of water resources are considered as threats in evaluating water resource security.
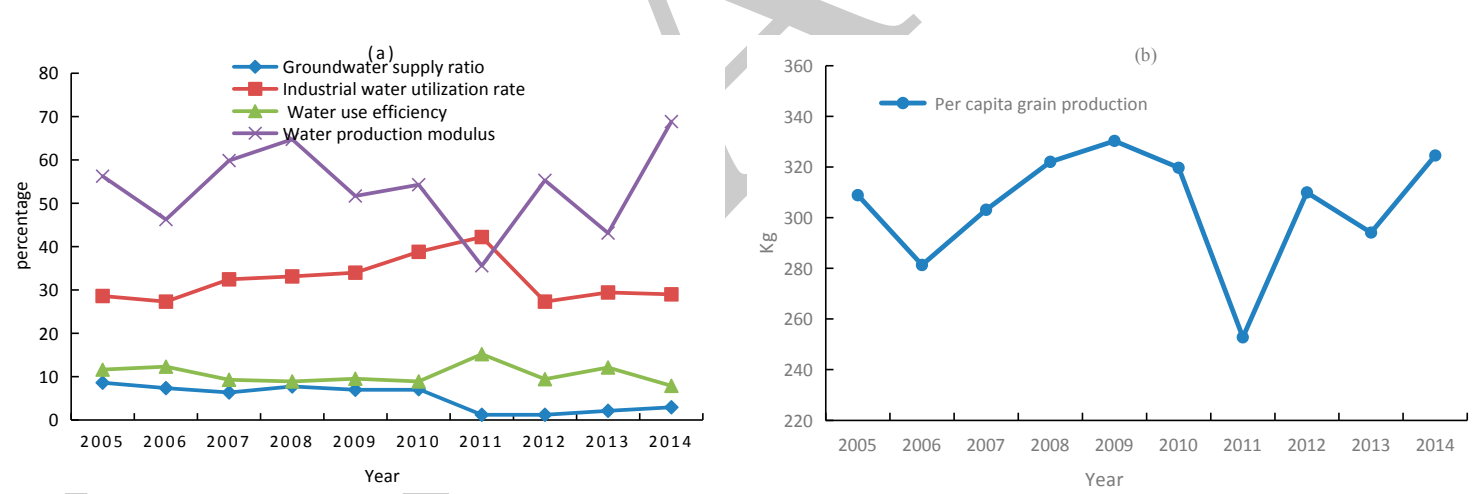

Figure 5. Obstacles to water resource security in the karst area. (a) Groundwater supply ratio, industrial water utilization rate, water use efficiency and water production modulus; (b) Per capita grain production.

\subsection{Driving Factors of Water Resource Security in the Karst Area}

As can be seen from Figure 6, in Guizhou Province from 2005 to 2014, the comprehensive utilization rate of industrial solid waste increased from $34.1 \%$ to $56.9 \%$, the qualifying rate of industrial wastewater increased from $67.7 \%$ to $89.5 \%$, above moderate rocky desertification area ratio decreased from $20.39 \%$ to $17.16 \%$, water requirement per unit GDP demand changed from $509 \mathrm{~m}^{3} / 10^{4} \mathrm{RMB}$ to $103 \mathrm{~m}^{3} / 10^{4} \mathrm{RMB}$, and the degree of development and utilization of groundwater decreased from $3.18 \%$ to $0.95 \%$. These five indices are the driving factors of water resource security. For a decrease or increase of 0.1 standard deviation units, the contribution to reducing the degree of deviation was $0.0328,0.0277,0.0214,0.0194$, and 0.0162 , respectively. 

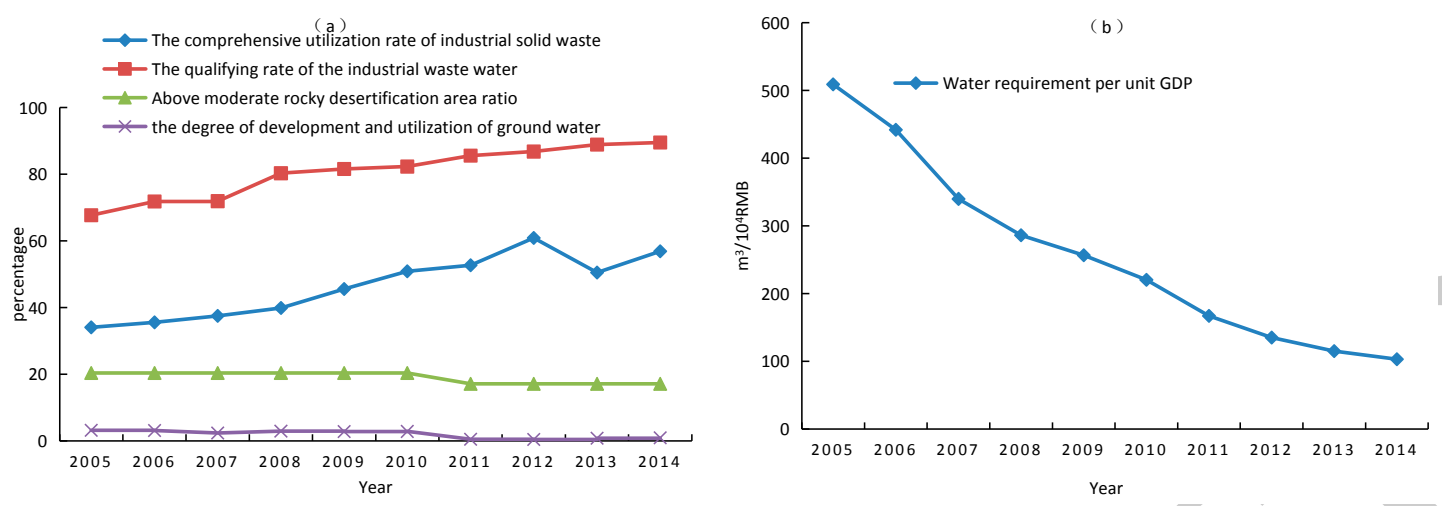

Figure 6. Driving factors of water resource security in the karst area. (a) The comprehensive utilization rate of industrial solid waste, the qualifying rate of the industrial waste water, above moderate rocky desertification area ratio and the degree of development and utilization of ground water; (b) Water requirement per unit GDP.

\subsection{Results of Water Resource Security Evaluation in the Karst Area}

The data of Table 4 were normalized and input into the trained BP network for testing to output the results, shown in Table 5 .

Table 5. Results of water resource security evaluation in the karst area based on the BP model.

\begin{tabular}{cccc}
\hline Order & Year & BP Model Output Value & BP Model Evaluation Results \\
\hline 1 & 2005 & 0.2312 & II \\
2 & 2006 & 0.2257 & II \\
3 & 2007 & 0.3571 & II \\
4 & 2008 & 0.3589 & II \\
5 & 2009 & 0.3737 & II \\
6 & 2010 & 0.4038 & III \\
7 & 2011 & 0.4159 & III \\
8 & 2012 & 0.4458 & III \\
9 & 2013 & 0.5012 & III \\
10 & 2014 & 0.4749 & III \\
\hline
\end{tabular}

The results (Table 5) show a general improvement of water resource security, which was at the moderate warning level from 2005 to 2009 and the critical safety level from 2010 to 2014.

\section{Discussion}

(1) The pattern of water resource exploitation and utilization is one of the main factors influencing water resource security in the karst area. As described in Table 2, the factors that have great influence on water resource security are groundwater supply ratio, degree of development and utilization of groundwater, water use efficiency, and water production modulus from the water environment subsystem. This is due to the special geological environment of the karst: the river is deep and the land is high, the land is leaky though rainfall is plentiful, the soil cover is less than the exposed rock, and the soil cover is too thin to maintain moisture. All this results in drought in the wet hot climate. The current situation in Guizhou is a lack of water resources in the engineering pattern. The uneven temporal and spatial distributions and the unreasonable development and utilization of water resources have caused increasingly severe shortages [24]. The study shows that this area lacks controlling water engineering, the moisture-holding capacity of the earth's surface is weak, the exploitation and utilization of surface water is insufficient, and the development and utilization of water resources is concentrated in only one way [25]. 
Therefore, Guizhou should take the characteristics of water resources and their formation into account to protect and utilize water resources. Rain collection, runoff gathering, water upgrade, underground and depression reservoirs, and lower dams on the surface are better patterns for karst water utilization. The lack of water in the karst area could be settled by dispersing storage, scattering supply, and breaking up the whole into parts. In addition, it is necessary to attach importance to the depth of water resource development, and to try to use surface water as much as possible to limit the blind exploitation of groundwater. Moreover, we should pay attention to the comprehensive development, rational utilization, and scientific management of surface water and groundwater.

(2) The main cause of the pressure on water resource security is rapid economic development. As can be seen from Table 2, the industrial water utilization rate, the comprehensive utilization rate of industrial solid waste, the qualifying rate of industrial wastewater, and the water requirement per unit GDP are the major factors affecting water resource security in the karst area. In particular, the total amount of wastewater discharge increased year by year, from 5.57 to 11.09 billion tons. Although the comprehensive utilization rate of industrial solid waste rose from $34.1 \%$ in 2005 to $60.9 \%$ in 2012 , it is still at the moderate warning level. This is because the main industries in Guizhou Province are mostly resource-based, with large consumption of resources and the environment. They are mainly labor-intensive and traditional industries, while high-tech and light industries are deficient. Because of the rapid development of industrial production, the amount of sewage and industrial water consumption is increasing, which has a negative impact on water resource security.

From the above analysis, we can see that with rapid economic development, especially industry, water resource security in the karst area has been under great pressure. In the future, adjusting the industrial structure will contribute to the optimal allocation of water resources and minimize consumption. It is necessary to carry out research on water-saving technologies for industries and change the economic structure from water-based to water-saving. Meanwhile, enterprises should be supported to increase their water recycling rate and strengthen their awareness of water conservation, so that a coordinated development of water resources and economics will be promoted for society.

(3) We should further reduce the rocky desertification area and improve the function of water regulation to karst water. The percentage of karst rock desertification accounts for $61.9 \%$ of Guizhou's total land, and karst desertification has further aggravated the degradation of water resources. In recent years, the proportion of rocky desertification area in Guizhou has decreased by $3.23 \%$ and the area of soil erosion has decreased by $12.31 \%$ (Table 4 ), which has had a positive effect on water resource security. It is an important way to solve the problem of a shortage of water resources in the karst area by strengthening the management of soil erosion, restoring vegetation, and reducing the rocky desertification area.

(4) On the whole, the water resource system in Guizhou is improving. From 2005 to 2009, water resource security was grim, at the moderate warning level. The main reason is that the rapid development of the economy and society is beyond the ability of the water resources to carry. Due to a lack of recognition and shortage of investment, construction of the environmental protection infrastructure lags behind urban development, which has caused severe water pollution and soil erosion. However, water resource security has improved since 2010 and has changed to the critical safety level. As can be seen, urbanization rate, treatment rate of urban wastewater, and qualifying rate of industrial wastewater have an upward trend (Table 4), whereas water requirement per unit GDP and above moderate rocky desertification area ratio have a downward trend (Figure 6). This is due to scientific development in recent years in Guizhou Province, with the government beginning to recognize the importance of sustainable development of water resources and strengthening their scientific management. During this period, the government has attached great importance to ecological protection, and has put the coordination of economic growth, population, resources, and environment in a prominent strategic position. Environmental protection investment has increased significantly. The proportion of environmental protection investment to GDP rose from 1.4\% in 2006 to $1.89 \%$ in 2014 
(Table 4). In addition, the capacity of urban sewage and corporate wastewater discharge should be further improved. These measures are an important part of changing water resource security.

Water resource security in Guizhou is at the critical safety level and has development potential. Overall, the current situation for water resources in Guizhou is in a fluctuating nonequilibrium state under the pressures of economic development and human disturbance. Further appropriate measures should be taken to promote sustainable utilization of water resources.

\section{Conclusions}

Based on data from Guizhou Province in the past 10 years, this paper constructs an MIV-BP model to evaluate water resource security. The results reflect the water resource security situation of this region more intuitively. The model has a certain reference value in karst areas. The main conclusions are drawn as follows:

(1) Based on the MIV-BP network model, the factors influencing water resource security in the karst area were selected and analyzed. The autonomous learning quality of the method reduces the dependence of the designer on prior knowledge, reduces the subjectivity of the influencing factors, and helps to establish a model with less independent elements and better effects. The evaluation results are objective and accurate. This study provides a theoretical reference for promoting the utilization of water resources in Guizhou Province and a way to evaluate water resource security in karst areas.

(2) Based on the composite system, including the water environment subsystem, social subsystem, economic subsystem, ecological subsystem, and human subsystem, an evaluation index of water resource security that can reflect the characteristics of the karst area is established. This study constructs a BP artificial neural network model to evaluate water resource security in the past 10 years. The results show that the water resource system in Guizhou has improved in the past 10 years. The pattern of water resource development and utilization and rapid economic development are the main factors influencing water resource development in the karst area. The results reflect the trend of water resource security in the karst area of Guizhou Province, which is consistent with the actual situation.

(3) The results of the MIV-BP neural network model only show the relative degree of influence of the factors affecting water resource security in the karst area. How they affect water resource security and their positive and negative correlation need to be further analyzed. In addition, because of the shortcomings of the MIV-BP neural network itself (many parameters and great flexibility), it needs to be trained several times to get a better prediction model. Meanwhile, the BP neural network itself has some shortcomings and deficiencies, so there is no absolutely accurate method for determining the number of hidden layers. It is generally obtained through trial and error, which will cause network redundancy. Therefore, this method needs to be further improved.

Author Contributions: D.G. and L.L. conceived and designed the research; L.L. and Q.Y. contributed to the collection of original data; L.L. and D.G. wrote the paper.

Funding: This research was funded by the National Science and Technology Planning Program in China (No. 2014BAB03B01), the Late Project of the National Social Science Foundation in China (No. 16FJY010), the National Natural Science Foundation of China (No. 41201546 and No. 41261038), the Natural Science Foundation of Chongqing in China (No. cstc2017jcyjAX0210), Science and Technology Fund of Guizhou Province, China ([2015]2001), National Key Research and Development Program of China (2016YFC0400708) and Chongqing Key Laboratory of Social Economy and Applied Statistic.

Acknowledgments: This work is partially supported by the National Science and Technology Planning Program in China (No. 2014BAB03B01), the Late Project of the National Social Science Foundation in China (No.16FJY010), the National Natural Science Foundation of China (No. 41201546 and No. 41261038), the Natural Science Foundation of Chongqing in China (No.cstc2017jcyjAX0210), and Chongqing Key Laboratory of Social Economy and Applied Statistics.

Conflicts of Interest: The authors declare no conflicts of interest. 


\section{References}

1. Li, B.; Wu, Q.; Chen, L. An analytical method of regional water resources carrying capacity in Karst area-A case study in Guizhou Province, China. Water Pract. Technol. 2016, 11, 796-805.

2. Chen, Y.; Li, B.; Li, Z.; Li, W. Water resource formation and conversion and water security in arid region of Northwest China. J. Geogra. Sci. 2016, 26, 939-952. [CrossRef]

3. Darras, T.; Raynaud, F.; Borrell Estupina, V. Neural network modeling and geochemical water analyses to understand and forecast karst and non-karst part of flash floods (case study on the Lez river, Southern France). Proc. Int. Assoc. Hydrol. Sci. 2015, 369, 43-48. [CrossRef]

4. Eftimi, R.; Zojer, H. Human impacts on Karst aquifers of Albania. Environ. Earth Sci. 2015, 74, 1-14. [CrossRef]

5. Green, P.A.; Vörösmarty, C.J.; Harrison, I.; Farrell, T.; Sáenz, L.; Fekete, B.M. Freshwater ecosystem services supporting humans: Pivoting from water crisis to water solutions. Glob. Environ. Chang. 2015, 34, $108-118$. [CrossRef]

6. Grey, D.; Sadoff, C.W. Sink or Swim? Water Security for Growth and Development. Water Policy 2007, 9, 545-571. [CrossRef]

7. Jiang, Y. China's water security: Current status, emerging challenges and future prospects. Environ. Sci. Policy 2015, 54, 106-125. [CrossRef]

8. Jin, J.L.; Wei, Y.M.; Zou, L.L.; Liu, L.; Zhang, W.W.; Zhou, Y.L. Forewarning of sustainable utilization of regional water resources: A model based on BP neural network and set pair analysis. Nat. Hazards 2012, 62, 115-127. [CrossRef]

9. Kongasiou, L.; Johannet, A.; Estupina, V.B.; Pistre, S. Neural networks for karst groundwater management: Case of the Lez spring (Southern France). Environ. Earth Sci. 2015, 74, 7617-7632. [CrossRef]

10. Lindhe, A.; Rosén, L.; Norberg, T.; Røstum, J.; Pettersson, T.J.R. Uncertainty modelling in multi-criteria analysis of water safety measures. Environ. Syst. Decis. 2013, 33, 195-208. [CrossRef]

11. Liotta, P.H. Boomerang effect: The convergence of national and human security. Secur. Dialogue 2002, 33, 473-488. [CrossRef]

12. Liu, M.; Xu, X.; Wang, D.; Sun, A.Y.; Wang, K. Karst catchments exhibited higher degradation stress from climate change than the non-karst catchments in southwest China: An ecohydrological perspective. J. Hydrol. 2016, 535, 173-180. [CrossRef]

13. Liu, Z.; Peng, C.; Xiang, W.; Tian, D.; Deng, X.; Zhao, M. Application of artificial neural networks in global climate change and ecological research: An overview. Chin. Sci. Bull. 2010, 55, 3853-3863. [CrossRef]

14. Lu, S.; Bao, H.; Pan, H. Urban water security evaluation based on similarity measure model of vague sets. Int. J. Hydrogen Energy 2016, 41, 15944-15950. [CrossRef]

15. Luan, Q.; Zhu, C. Surface Water Quality Evaluation Using BP and RBF Neural Network. J. Softw. 2011, 6, 2528-2534. [CrossRef]

16. Trappe, M. Modern resource use and its impact to karst water resources. Z. Geomorphol. Suppl. 2016, 60, 153-174. [CrossRef]

17. Vörösmarty, C.J.; Mcintyre, P.B.; Gessner, M.O.; Dudgeon, D.; Prusevich, A.; Green, P.; Glidden, S.; Bunn, S.E.; Sullivan, C.A.; Liermann, C.R.; et al. Global threats to human water security and river biodiversity. Nature 2010, 467, 555-561. [CrossRef] [PubMed]

18. Wang, X. 43 Cases Analysis of MATLAB Neural Network; Beijing University of Aeronautics and Astronautics Press: Beijing, China, 2013; pp. 80-82.

19. Waughrayd. Water Security: The Water-Food-Energy-Climate Nexus; Island Press: Washington, DC, USA, 2011; pp. 1-10.

20. Wu, G.; Li, L.; Ahmad, S.; Chen, X.; Pan, X. A dynamic model for vulnerability assessment of regional water resources in arid areas: A case study of Bayingolin, China. Water Resour. Manag. 2013, 27, 3085-3101. [CrossRef]

21. Yang, J.; Lei, K.; Khu, S.; Meng, W. Assessment of water resources carrying capacity for sustainable development based on a system dynamics model: A case study of Tieling City, China. Water Resour. Manag. 2015, 29, 885-899. [CrossRef]

22. Yang, Q.; Zhang, F.; Jiang, Z.; Yuan, D.; Jiang, Y. Assessment of water resource carrying capacity in karst area of Southwest China. Environ. Earth Sci. 2016, 75, 1-8. [CrossRef] 
23. Yang, Y.M.; Yang, Y.H.; Moiwo, J.P.; Hu, Y.K. Estimation of irrigation requirement for sustainable water resources reallocation in North China. Agric. Water Manag. 2010, 97, 1711-1721. [CrossRef]

24. You, H. Assessing Land Ecological Security Based on BP Neural Network: A case study of Hangzhou, China. J. Comput. 2013, 8, 1394-1400. [CrossRef]

25. Zhang, J.Y.; Wang, L.C. Assessment of water resource security in Chongqing City of China: What has been done and what remains to be done? Nat. Hazards 2015, 75, 2751-2772. [CrossRef] 